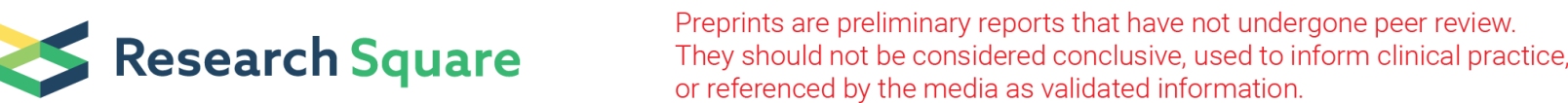

\section{The bevacizumab plus oxaliplatin-based chemotherapy regimen is more suitable for metastatic colorectal cancer patients with a history of schistosomiasis}

\section{Li-Na Zhou}

Affiliated Kunshan Hospital of Jiangsu University

\section{Li-Qiang Weng}

Affiliated Kunshan Hospital of Jiangsu University

\section{Chun-Xia Feng}

Affiliated Kunshan Hospital of Jiangsu University

\section{Yan Zhang}

Affiliated Kunshan Hospital of Jiangsu University

\section{Ping Li}

Affiliated Kunshan Hospital of Jiangsu University

Min Tang

Affiliated Kunshan Hospital of Jiangsu University

Min-Bin Chen ( $\nabla$ cmb1981@163.com )

Jiangsu University https://orcid.org/0000-0003-1453-8664

Research article

Keywords: bevacizumab, oxaliplatin, irinotecan, splenic enlargement, thrombocytopenia

Posted Date: December 9th, 2019

DOI: https://doi.org/10.21203/rs.2.18346/v1

License: (c) (i) This work is licensed under a Creative Commons Attribution 4.0 International License. Read Full License 


\section{Abstract}

Background: People suffer from schistosomiasis, leading to liver fibrosis, splenomegaly and thrombocytopenia. The effects of bevacizumab plus oxaliplatin or irinotecan-based chemotherapy regimens on platelets are different, but have not been determined. We conducted a retrospective analysis in metastatic colorectal cancer ( $\mathrm{mCRC}$ ) patients evaluating the impact of bevacizumab on platelet, in order to find a more suitable plan for mCRC patients with a history of schistosomiasis.

Methods: The medical records of all mCRC patients with a history of schistosomiasis who received FOLFOX or FOLFIRI with or without bevacizumab from September 1, 2017 to June 30, 2019 in Kunshan Hospital were reviewed. Platelet counts and spleen sizes were compared from the first cycle until completion of chemotherapy.

Results: Evaluable splenic enlargement and thrombocytopenia results were obtained from 73 Bevacizumab-treated patients and 80 non-bevacizumab treated patients. In patients treated with oxaliplatin, the rates of splenic enlargement $(19.5 \%$ vs. $66.7 \%, P=0.01)$ and thrombocytopenia ( $31.7 \%$ vs. $77.2 \%, P=0.02)$ were lower in the bevacizumab-treated cohort than that in the nonbevacizumab cohort. When stratified for irinotecan, there were no statistical differences of frequency of splenic enlargement between the two groups, however, the rates of thrombocytopenia were higher in the bevacizumab-treated cohort than that in the nonbevacizumab cohort $(59.4 \%$ vs. $8.7 \%, P=0.01)$.

Conclusion: The bevacizumab plus oxaliplatin-based chemotherapy regimen is more suitable for mCRC patients with a history of schistosomiasis, especially for lower platelet count patients.

\section{Introduction}

There were about 12 million schistosomiasis patients in China in 1950s.[1] Although great achievements have been attained in the control of that, there were still 37,601 schistosomiasis patients in China at the end of 2017.[2] Kunshan city lies in the Yangtze river basin, which is the endemic area of schistosomiasis, [1] people here suffered a lot from schistosomiasis and the resulting hepatic fibrosis, splenomegaly and thrombocytopenia. Their basic platelet counts were low, so the impact of chemotherapy on platelet counts was important for them. If the platelets do not meet the requirements of chemotherapy, the patient's treatment will not be carried out, directly affecting the prognosis.

Oxaliplatin or irinotecan in combination with 5-fluorouracil regimens are back bones of systemic treatment for metastatic or recurrent colorectal cancer patients. Their impacts on thrombocytopenia are different. Angiogenesis represents an attractive therapeutic target for patients with cancer.[3] Bevacizumab (Avastin, Genentech, South San Francisco, CA) is a recombinant humanized immunoglobulin monoclonal antibody that binds and inhibits the biological activity of human vascular endothelial growth factor-A (VEGF-A).[4] Bevacizumab enhances the effect of chemotherapy in colorectal cancer and was approved by FDA for the treatment of metastatic colorectal cancer as the first angiogenesis inhibitor.[5] Its main adverse effects are hypertension, proteinuria, thromboembolic events, 
wound-healing complications, congestive heart failure and gastrointestinal perforation.[6-11] The impact of bevacizumab to chemotherapy upon thrombocytopenia is unknown, it varied among clinical trials. Many studies reported that bevacizumab was associated with increased risk of all-grade thrombocytopenia. $[12,13]$ It increased the incidence of grade 1 or 2 thrombocytopenia from irinotecan based chemotherapy in patients with metastatic colorectal cancer.[5, 14] However, it was reported that bevacizumab could reduce the rate of thrombocytopenia from oxaliplatin based chemotherapy, because of its protective impact upon oxaliplatin-induced hepatic sinusoidal injury (HSI).[15-17] In order to find a more suitable plan for patients with metastatic colorectal cancer with low platelets, we conducted a retrospective analysis evaluating the impact of bevacizumab on platelet in metastatic colorectal cancer (mCRC) patients.

\section{Patients And Methods}

\section{Patients}

This study was conducted under the approval of Affiliated Kunshan Hospital of Jiangsu University Institutional Review Board, and due to the retrospective nature of the study, a waiver of informed consent was obtained. Bevacizumab was widely used in China since September 1, 2017 because it wasn't covered by insurance until then. We retrospectively reviewed the medical records of all patients with mCRC who received FOLFOX or FOLFIRI from September 1, 2017 to June 30, 2019 in Affiliated Kunshan Hospital of Jiangsu University. The inclusion criteria included: mCRC patients, schistosomiasis treatment history, have received FOLFOX or FOLFIRI as first-line treatment for no less than 4 cycles. The following exclusion criteria were then applied to the identified cases: fluoropyrimidine or capecitabine single agent chemotherapy, cetuximab containing regimen, absence of spleen on imaging, lack of counts of platelets.

\section{Data Collection}

The baseline data collected consisted of patient demographics, body mass index (BMI) and disease characteristics. From the first cycle until completion of chemotherapy, data were collected on platelet counts, numbers of cycles delivered and spleen sizes. Contrast-enhanced CT studies were performed with a multidetector row-64 CT scanner (Light-Speed, GE Healthcare) using a collimation of $5 \mathrm{~mm}$.

\section{Statistical Analysis}

Comparisons between groups were carried out with the Fisher exact test and Wilcoxon rank-sum test. Time-to-event distributions were estimated by the Kaplan-Meier curves, and variable comparison between treatment groups was made using the Log-rank test. The Cox proportional hazards regression model was utilized to characterize associations between patient characteristics and the incidences of splenomegaly and thrombocytopenia. All statistical analyses were performed via Stata 14.0 (StataCorp, College Station, TX). All the statistical tests were two-sided, and $\mathrm{P}<0.05$ was considered statistically significant.

\section{Results}




\section{The baseline characteristics}

The final population analyzed consisted of 153 patients, including 73 bavacizumab-treated patients and 80 nonbevacizumab-treated patients. Baseline characteristics including age, sex, BMI, tumor site, chemotherapy cycles, spleen size and platelet count for two groups were similar (Table1). The median age of patients was 63 (51-79) and 58 (53-89) for the bavacizumab cohort and non bavacizumab cohort respectively $(P=0.12)$. Sex $(P=0.50)$ and tumor site $(P=0.33)$ of patients was equally distributed in the two groups. Body mass index (BMI) was calculated as weight $[\mathrm{kg}] /(\text { height }[\mathrm{m}])^{2}$. The median values were 21.1 (15.5-29.2) and 21.5 (15.9-33.8) for the bevacizumab and nonbevacizumab group respectively $(P=0.64)$. The median chemotherapy cycles (6 (6-24) vs. $6(6-16), P=0.68)$, median baseline spleen size (152.2 (74.1-529.6) vs. $150.0(69.5-410.8), P=0.11)\left(\mathrm{cm}^{3}\right)$ and median baseline platelet count (162 (77-441) vs. 166 (69-532), $P=0.90)(\mathrm{K} / \mathrm{uL})$ did not differ significantly between the two groups as well.

\section{Bevacizumab had impact on the rate of thrombocytopenia from chemotherapy}

In bevacizumab-treated cohort, the six-month cumulative incidence rates of splenic enlargement of $10 \%$ or greater and thrombocytopenia were similar between the oxaliplatin group and irinotecan group. In nonbevacizumab-treated cohort, the incidence rates of splenic enlargement were similar between the two groups while the rates of thrombocytopenia were lower in the irinotecan group (Table2).

\section{Bevacizumab decreased the rate of thrombocytopenia from oxaliplatin}

Of the 98 patients treated with oxaliplatin and fluoropyrimidine, 41 received bevacizumab. Of the 55 patients treated with irinotecan and fluoropyrimidine, 32 received bevacizumab. There were no statistical differences between the groups (Table3). The results of analyses were presented in Table4, Figure1A and Figure 1B.

In patients treated with oxaliplatin, the six-month cumulative incidence rates of splenic enlargement of $10 \%$ or greater were lower in the bevacizumab-treated cohort than in the nonbevacizumab cohort $(19.5 \%$ vs. $66.7 \%, P=0.01$ ) (Fig $2 A \otimes 2 C \otimes 2 D$ ). There was no splenic enlargement more than $20 \%$ in the bevacizumab-treated cohort. The median time to splenic enlargement of $10 \%$ or greater in patients treated with oxaliplatin was longer in the bevacizumab cohort, but the difference was not significant $(120 \mathrm{~d}(4.0 \mathrm{~m})$ vs. $103 \mathrm{~d}(3.4 \mathrm{~m}), P=0.85)$. The six-month cumulative incidence rates of thrombocytopenia were lower in the bevacizumab-treated cohort than in the nonbevacizumab cohort ( $31.7 \%$ vs. $77.2 \%$, $P=0.02$ ) (Fig 2B), especially for grade 1 thrombocytopenia ( $22.0 \%$ vs. $57.9 \%, P=0.02)$. The difference was not significant for that of grade 2 thrombocytopenia ( $9.8 \%$ vs. $19.3 \%, P=0.40)$. There was no grade 3 thrombocytopenia. The median time to thrombocytopenia was shorter in the bevacizumab-treated cohort than the nonbevacizumab cohort $(23 \mathrm{~d}(0.8 \mathrm{~m})$ vs. 33d $(1.1 \mathrm{~m}), P=0.02)$. In patients with liver metastasis, the six-month cumulative incidence rates of splenic enlargement of $10 \%$ or greater $(26.1 \% \mathrm{vs.} 60.6 \%$, $P=0.14)$ and thrombocytopenia ( $43.5 \%$ vs. $75.8 \%, P=0.27)$ were similar in the bevacizumab-treated cohort and nonbevacizumab cohort. In patients without liver metastasis, the rates were lower in the bevacizumab-treated cohort than in the nonbevacizumab cohort $(11.1 \%$ vs. $75.0 \%, P=0.01,16.7 \%$ vs. 
$79.2 \%, P=0.03)$. In patients with splenic enlargement of more than $10 \%$, comparing the bevacizumab and nonbevacizumab-treated cohort, the six-month cumulative incidence rates of thrombocytopenia were similar $(50.0 \%(4 / 8)$ vs. $78.9 \%(30 / 38), P=0.54)$. In patients with reduced splenic volume, the incidence rates were similar as well $(35.0 \%(7 / 20)$ vs. $67.7 \%(10 / 15), P=0.37)$.

\section{Bevacizumab increased the rate of thrombocytopenia from irinotecan}

In patients treated with irinotecan, the six-month cumulative incidence rates of splenic enlargement of $10 \%$ or greater ( $28.1 \%$ vs. $26.1 \%, P=1.00$ ) (Fig $3 \mathrm{~A} \varangle 3 \mathrm{C} \otimes 3 \mathrm{D}$ ) and median time to splenic enlargement (130d $(4.3 \mathrm{~m})$ vs. $140 \mathrm{~d}(4.7 \mathrm{~m}), P=0.80)$ were similar between the bevacizumab and nonbevacizumab cohort. If we use a higher threshold of $20 \%$ or $30 \%$, the rates were similar as well $(18.8 \%$ vs. $17.4 \%, P=1.00 ; 6.3 \%$ vs. $8.7 \%, P=1.00)$. The six-month cumulative incidence rates of thrombocytopenia were higher in the bevacizumab-treated cohort than in the nonbevacizumab cohort ( $59.4 \%$ vs. $8.7 \%, P=0.01$ ) (Fig 3B). The difference was significant for that of grade 1 thrombocytopenia $(46.9 \%$ vs. $8.7 \%, P=0.04$ ). There was no grade 2 thrombocytopenia in the nonbevacizumab-treated cohort, and no grade 3 thrombocytopenia in both cohorts. The median time to thrombocytopenia was shorter in the bevacizumab-treated cohort (10d $(0.3 \mathrm{~m})$ vs. $64 \mathrm{~d}(2.1 \mathrm{~m}), P=0.01)$. No matter in patients with or without liver metastasis, the six-month cumulative incidence rates of splenic enlargement of $10 \%$ or greater $(36.4 \%$ vs. $20.0 \%, P=0.66 ; 23.8 \%$ vs. $30.8 \%, \mathrm{P}=1.00)$ and thrombocytopenia ( $63.6 \%$ vs. $10.0 \%, \mathrm{P}=0.11 ; 57.1 \%$ vs. $7.7 \%, \mathrm{P}=0.07)$ were both similar in the bevacizumab-treated cohort and nonbevacizumab cohort. In patients with splenic enlargement of more than $10 \%$, comparing the bevacizumab and nonbevacizumab-treated cohort, the sixmonth cumulative incidence rates of thrombocytopenia were similar $(66.7 \%(6 / 9)$ vs. $9.1 \%(1 / 11), P=0.09)$. In patients with reduced splenic volume, the incidence rates were similar as well $(50.0 \%(7 / 14)$ vs. $8.3 \%$ $(1 / 12), P=0.12)$.

\section{Discussion}

Human schistosomiasis is a snail-borne disease caused by worms of the genus Schistosoma. It's a serious public health problem worldwide, threatening 800 million people in 78 countries with a loss of 70 million disability-adjusted life years. As one of the countries suffering from schistosomiasis greatly, China has carried out active control measures over the past six decades and has made great achievements in schistosomiasis controlling. However, the eggs of Schistosoma deposited in the liver tissues could elicite granulomatous response, leading to continuous fibrosis of periportal fibrosis, and the resulting liver cirrhosis, portal hypertension, splenomegaly, and thrombocytopenia.[18] Kunshan city is the endemic area of schistosomiasis. The baseline platelet counts of patients in this study were lower than that of Overman et al.'s study (median platelet count: 162 vs. 320 in bevacizumab cohort, 166 vs. 304 in nonbevacizumab cohort; range of platelet count: 77-441 vs. 161-1013 in bevacizumab cohort, 69-532 vs. 151-887 in nonbevacizumab cohort) (K/uL). This may be due to schistosomiasis and the resulting liver fibrosis and splenomegaly. So our patients are more likely to encounter thrombocytopenia during chemotherapy which may lead to increased risk of bleeding, greater blood transfusion requirement, 
treatment delay, chemotherapy dose reduction, or even discontinuation of chemotherapy. Figuring out the effect of chemotherapy drugs on platelet counts is more important for them.

This study shows that bevacizumab decreases the rate of thrombocytopenia from oxaliplatin-based chemotherapy, but increases that from irinotecan-based chemotherapy. Bevacizumab decreases the rate of splenic enlargement from oxaliplatin-based chemotherapy, but doesn't change that from irinotecanbased chemotherapy. We got similar results when we stratified patients with splenic enlargement and shrink.

Thrombocytopenia is a prominent side effect seen during oxaliplatin treatment, occurring in up to $70 \%$ of patients. Bone marrow suppression, hypersplenism, non-immune microangiopathy and immune-mediated thrombocytopenia are main mechanisms of thrombocytopenia.[19] It could also be associated with splenic enlargement as a result of oxaliplatin-induced HSI.[20-22] Sinusoidal injury was described as a disruption of the sinusoidal endothelium leading to subsequent collagen deposition in the perisinusoidal space and veno-occlusive fibrosis. It may result in portal hypertension and splenomegaly with associated thrombocytopenia.[23, 24] Bevacizumab protect againt HSI by reducing the extent and incidence of sinusoidal dilatation, reducing the incidence of perisinusoidal fibrosis and hepatocellular necrosis,[2527] which reduced the rate of thrombocytopenia and the frequency of splenomegaly.[15] It's consistent with our current results. In our study we found that the six-month cumulative incidence rates of splenic enlargement and thrombocytopenia were lower in the bevacizumab-treated cohort than in the nonbevacizumab cohort. In patients without liver metastasis, we drew similar conclusions. In patients with liver metastasis, the rates were lower in the bevacizumab-treated cohort, while the differences were not significant $(26.1 \%$ vs. $60.6 \%, P=0.14 ; 43.5 \%$ vs. $75.8 \%, P=0.27)$. It may be because of the interference of liver metastasis on the protective effect of bevacizumab on oxaliplatin-induced splenomegaly or the small number of patients involved in this study.

Irinotecan, a synthetic analog of camptothecin, is a topoisomerase I inhibitor. Its dominant hematologic side effect is neutropenia, while thrombocytopenia, when it occurs, is usually mild. It was reported bevacizumab increased the incidence of thrombocytopenia from irinotecan based chemotherapy ( $5 \%$ vs. $0 \%$ in patients with metastatic colorectal cancer, $[5,14]$ however, some other studies showed that the addition of bevacizumab to irinotecan-based chemotherapy did not alter the incidence of thrombocytopenia. [28-30] Our study shows that in patients treated with irinotecan, the six-month cumulative incidence rates of thrombocytopenia are much higher in the bevacizumab-treated cohort than in the nonbevacizumab cohort $(59.4 \%$ vs. $8.7 \%, P=0.01)$. In patients with or without liver metastasis, the rates were both higher in the bevacizumab-treated cohort, while the differences were not significant $(63.6 \%$ vs. $10.0 \%, P=0.11 ; 57.1 \%$ vs. $7.7 \%, P=0.07)$. It may be due to the small number of patients involved in this study. Thrombocytopenia can be because of platelet dysfunction, consumption leading to shortened platelet half-life and exhausting of compensatory mechanisms of the bone marrow caused by bevacizumab. These may be the reasons for the increased incidence of thrombocytopenia by bevacizumab from irinotecan. 
Our study adds evidence of protective effect of bevacizumab on oxaliplatin-induced splenomegaly, which is a surrogate for $\mathrm{HSI}$, and resultant reductions in thrombocytopenia in metastatic colorectal cancer patients. The data suggests that we can get a better understanding of changes in platelet counts by monitoring changes in spleen size during oxaliplatin-based chemotherapy. Additional work is needed to identify patients at greatest risk for oxaliplatin-induced HSI and might derive benefit from bevacizumab with regard to its ability of reducing the rate of thrombocytopenia. This study shows that bevacizumab increases the incidence of thrombocytopenia from irinotecan. Additional work is needed to identify patients at greatest risk for increased rate of thrombocytopenia, for whom dose reduction or regimen adjustment should be considered. With a better understanding of impact of drugs on platelet count, we can now select regimen more suitable for patients here, whose baseline platelet counts are lower and are more likely to encounter thrombocytopenia.

To minimize investigator bias in this study, the evaluator calculating the spleen size, was blinded to the chemotherapy regimen. However our study still has limitations that we should point out. First, this is a retrospective study; there might be bias due to unidentified confounders. The decision for bevacizumab use was made by the treating physician who can be influenced by additional factors. Second, although the patients involved in this study had schistosomiasis treatment history, they didn't necessarily have splenomegaly, and it wasn't easy to assess hepatic fibrosis statement for each patient. Third, the number of patients in this study was relatively small. Fourth, as treatment delays and dose adjustments were not only based on platelet count, but also other clinical and laboratory factors, we could not isolate impact of thrombocytopenia upon chemotherapy dose intensity. Fifth, the interaction of impact of Schistosoma on liver fibrosis and thrombocytopenia with that of Oxaliplatin is unknown. Prospective randomized and larger cohort studies are needed to confirm our findings.

\section{Conclusion}

Bevacizumab decreases the rate of thrombocytopenia in oxaliplatin-based group; however, it increases thrombocytopenia in irinotecan-based group. For mCRC patients with a history of schistosomiasis, maybe it's better to choose the regimen of bevacizumab with oxaliplatin, especially for lower platelet count patients. Further studies are required to verify our findings.

\section{Declarations}

This study was conducted under the approval of Affiliated Kunshan Hospital of Jiangsu University Institutional Review Board, and due to the retrospective nature of the study, a waiver of informed consent was obtained. Consent for publication is not applicable. The datasets used and analysed during the current study are available from the corresponding author on reasonable request. The authors declare that they have no competing interests. This work is supported by the National Natural Science Foundation (81773192); Natural Science Foundation of Jiangsu Province (BK20171248); Jiangsu Youth Medical Talents Project (QNRC2016527); Jiangsu Province "333 Project" Research Projects (2016-III0367); The Foundation of tumor clinical and basic research team (KYC005). MBC desined the work and 
substantively revised it. LNZ collected the data and was a major contributor in writing the manuscript. LQW measured, calculated and compared the spleen sizes. CXF contributed in writing the manuscript. YZ analyzed the data. PL interpreted the data. MT revised the work. Acknowledgements are not applicable.

\section{Abbreviations}

metastatic colorectal cancer (mCRC); vascular endothelial growth factor-A (VEGF-A); hepatic sinusoidal injury (HSI).

\section{References}

1. Wu W, Feng A, Huang Y: Research and control of advanced schistosomiasis japonica in China. Parasitology research 2015, 114(1):17-27.

2. Li-Juan Z, Zhi-Min X, Si-Min D, Hui D, Shan L, Jing X, Shi-Zhu L, Xiao-Nong Z: [Endemic status of schistosomiasis in People's Republic of China in 2017]. Zhongguo xue xi chong bing fang zhi za zhi = Chinese journal of schistosomiasis control 2018, 30(5):481-488.

3. Cook KM, Figg WD: Angiogenesis inhibitors: current strategies and future prospects. CA: a cancer journal for clinicians 2010, 60(4):222-243.

4. Ferrara N, Hillan KJ, Gerber HP, Novotny W: Discovery and development of bevacizumab, an antiVEGF antibody for treating cancer. Nature reviews Drug discovery 2004, 3(5):391-400.

5. Hurwitz H, Fehrenbacher L, Novotny W, Cartwright T, Hainsworth J, Heim W, Berlin J, Baron A, Griffing $\mathrm{S}$, Holmgren E et al: Bevacizumab plus irinotecan, fluorouracil, and leucovorin for metastatic colorectal cancer. The New England journal of medicine 2004, 350(23):2335-2342.

6. Ranpura V, Pulipati B, Chu D, Zhu X, Wu S: Increased risk of high-grade hypertension with bevacizumab in cancer patients: a meta-analysis. American journal of hypertension 2010, 23(5):460468.

7. Wu S, Kim C, Baer L, Zhu X: Bevacizumab increases risk for severe proteinuria in cancer patients. Journal of the American Society of Nephrology : JASN 2010, 21(8):1381-1389.

8. Nalluri SR, Chu D, Keresztes R, Zhu X, Wu S: Risk of venous thromboembolism with the angiogenesis inhibitor bevacizumab in cancer patients: a meta-analysis. Jama 2008, 300(19):2277-2285.

9. Schutz FA, Je Y, Azzi GR, Nguyen PL, Choueiri TK: Bevacizumab increases the risk of arterial ischemia: a large study in cancer patients with a focus on different subgroup outcomes. Annals of oncology : official journal of the European Society for Medical Oncology 2011, 22(6):1404-1412.

10. Choueiri TK, Mayer EL, Je Y, Rosenberg JE, Nguyen PL, Azzi GR, Bellmunt J, Burstein HJ, Schutz FA: Congestive heart failure risk in patients with breast cancer treated with bevacizumab. Journal of clinical oncology : official journal of the American Society of Clinical Oncology 2011, 29(6):632-638.

11. Hapani S, Chu D, Wu S: Risk of gastrointestinal perforation in patients with cancer treated with bevacizumab: a meta-analysis. The Lancet Oncology 2009, 10(6):559-568. 
12. Tebbutt NC, Wilson K, Gebski VJ, Cummins MM, Zannino D, van Hazel GA, Robinson B, Broad A, Ganju V, Ackland SP et al: Capecitabine, bevacizumab, and mitomycin in first-line treatment of metastatic colorectal cancer: results of the Australasian Gastrointestinal Trials Group Randomized Phase III MAX Study. Journal of clinical oncology : official journal of the American Society of Clinical Oncology 2010, 28(19):3191-3198.

13. Van Cutsem E, Vervenne WL, Bennouna J, Humblet Y, Gill S, Van Laethem JL, Verslype C, Scheithauer $\mathrm{W}$, Shang $\mathrm{A}$, Cosaert $\mathrm{J}$ et al: Phase III trial of bevacizumab in combination with gemcitabine and erlotinib in patients with metastatic pancreatic cancer. Journal of clinical oncology : official journal of the American Society of Clinical Oncology 2009, 27(13):2231-2237.

14. Hurwitz HI, Fehrenbacher L, Hainsworth JD, Heim W, Berlin J, Holmgren E, Hambleton J, Novotny WF, Kabbinavar F: Bevacizumab in combination with fluorouracil and leucovorin: an active regimen for first-line metastatic colorectal cancer. Journal of clinical oncology : official journal of the American Society of Clinical Oncology 2005, 23(15):3502-3508.

15. Overman MJ, Maru DM, Charnsangavej C, Loyer EM, Wang H, Pathak P, Eng C, Hoff PM, Vauthey JN, Wolff RA et al: Oxaliplatin-mediated increase in spleen size as a biomarker for the development of hepatic sinusoidal injury. Journal of clinical oncology : official journal of the American Society of Clinical Oncology 2010, 28(15):2549-2555.

16. Allegra CJ, Yothers G, O'Connell MJ, Sharif S, Colangelo LH, Lopa SH, Petrelli NJ, Goldberg RM, Atkins JN, Seay TE et al: Initial safety report of NSABP C-08: A randomized phase III study of modified FOLFOX6 with or without bevacizumab for the adjuvant treatment of patients with stage II or III colon cancer. Journal of clinical oncology : official journal of the American Society of Clinical Oncology 2009, 27(20):3385-3390.

17. Overman MJ, Ferrarotto R, Raghav K, George B, Qiao W, Machado KK, Saltz LB, Mazard T, Vauthey JN, Hoff PM et al: The Addition of Bevacizumab to Oxaliplatin-Based Chemotherapy: Impact Upon Hepatic Sinusoidal Injury and Thrombocytopenia. Journal of the National Cancer Institute 2018, 110(8):888-894.

18. Song LG, Wu XY, Sacko M, Wu ZD: History of schistosomiasis epidemiology, current status, and challenges in China: on the road to schistosomiasis elimination. Parasitology research 2016, 115(11):4071-4081.

19. Jardim DL, Rodrigues CA, Novis YA, Rocha VG, Hoff PM: Oxaliplatin-related thrombocytopenia. Annals of oncology : official journal of the European Society for Medical Oncology 2012, 23(8):19371942.

20. May D, Djonov V, Zamir G, Bala M, Safadi R, Sklair-Levy M, Keshet E: A transgenic model for conditional induction and rescue of portal hypertension reveals a role of VEGF-mediated regulation of sinusoidal fenestrations. PloS one 2011, 6(7):e21478.

21. Kopetz S, Lesslie DP, Dallas NA, Park SI, Johnson M, Parikh NU, Kim MP, Abbruzzese JL, Ellis LM, Chandra J et al: Synergistic activity of the SRC family kinase inhibitor dasatinib and oxaliplatin in colon carcinoma cells is mediated by oxidative stress. Cancer research 2009, 69(9):3842-3849. 
22. Yokomori H, Oda M, Yoshimura K, Nagai T, Ogi M, Nomura M, Ishii H: Vascular endothelial growth factor increases fenestral permeability in hepatic sinusoidal endothelial cells. Liver international : official journal of the International Association for the Study of the Liver 2003, 23(6):467-475.

23. Rubbia-Brandt L, Audard V, Sartoretti P, Roth AD, Brezault C, Le Charpentier M, Dousset B, Morel P, Soubrane $\mathrm{O}$, Chaussade $S$ et al: Severe hepatic sinusoidal obstruction associated with oxaliplatinbased chemotherapy in patients with metastatic colorectal cancer. Annals of oncology : official journal of the European Society for Medical Oncology 2004, 15(3):460-466.

24. Aloia T, Sebagh M, Plasse M, Karam V, Levi F, Giacchetti S, Azoulay D, Bismuth H, Castaing D, Adam R: Liver histology and surgical outcomes after preoperative chemotherapy with fluorouracil plus oxaliplatin in colorectal cancer liver metastases. Journal of clinical oncology : official journal of the American Society of Clinical Oncology 2006, 24(31):4983-4990.

25. Klinger M, Eipeldauer S, Hacker S, Herberger B, Tamandl D, Dorfmeister M, Koelblinger C, Gruenberger $B$, Gruenberger $T$ : Bevacizumab protects against sinusoidal obstruction syndrome and does not increase response rate in neoadjuvant XELOX/FOLFOX therapy of colorectal cancer liver metastases. European journal of surgical oncology : the journal of the European Society of Surgical Oncology and the British Association of Surgical Oncology 2009, 35(5):515-520.

26. Ribero D, Wang H, Donadon M, Zorzi D, Thomas MB, Eng C, Chang DZ, Curley SA, Abdalla EK, Ellis $\mathrm{LM}$ et al: Bevacizumab improves pathologic response and protects against hepatic injury in patients treated with oxaliplatin-based chemotherapy for colorectal liver metastases. Cancer 2007, 110(12):2761-2767.

27. Rubbia-Brandt L, Lauwers GY, Wang H, Majno PE, Tanabe K, Zhu AX, Brezault C, Soubrane O, Abdalla EK, Vauthey JN et al: Sinusoidal obstruction syndrome and nodular regenerative hyperplasia are frequent oxaliplatin-associated liver lesions and partially prevented by bevacizumab in patients with hepatic colorectal metastasis. Histopathology 2010, 56(4):430-439.

28. Stathopoulos GP, Batziou C, Trafalis D, Koutantos J, Batzios S, Stathopoulos J, Legakis J, Armakolas A: Treatment of colorectal cancer with and without bevacizumab: a phase III study. Oncology 2010, 78(5-6):376-381.

29. Guan ZZ, Xu JM, Luo RC, Feng FY, Wang LW, Shen L, Yu SY, Ba Y, Liang J, Wang D et al: Efficacy and safety of bevacizumab plus chemotherapy in Chinese patients with metastatic colorectal cancer: a randomized phase III ARTIST trial. Chinese journal of cancer 2011, 30(10):682-689.

30. Cao R, Zhang S, Ma D, Hu L: A multi-center randomized phase II clinical study of bevacizumab plus irinotecan, 5-fluorouracil, and leucovorin (FOLFIRI) compared with FOLFIRI alone as second-line treatment for Chinese patients with metastatic colorectal cancer. Medical oncology 2015, 32(1):325.

\section{Tables}

Table1. Characteristics of patients involved 


\begin{tabular}{llll}
\hline characteristics & Bevacizumab cohort(n=73) & Nonbevacizumab cohort( $\mathrm{n}=80)$ & $P$-value \\
\hline Age, median (range), $\mathrm{y}$ & $63 \square 51-79 \square$ & $58(53-89)$ & 0.12 \\
Sex, No.(\%) & & & \\
Female & $24 \llbracket 32.9 \square$ & $31(38.8)$ & 0.50 \\
Male & $49 \square 67.1 \square$ & $49(61.2)$ & \\
BMl, median(range), $\mathrm{kg} / \mathrm{m}^{2}$ & $21.1015 .5-29.2 \square$ & $21.5 \square 15.9-33.8 \square$ & 0.64 \\
Tumor site, No.(\%) & & & \\
Colon & $45 \square 61.6 \square$ & $43(53.8)$ & 0.33 \\
Rectum & $28 \square 38.4 \square$ & $37(46.2)$ & \\
Chemotherapy cycles, median (range) & $6 \square 6-24 \square$ & $6 \square 6-16 \square$ & 0.68 \\
Baseline spleen size, median (range), cm ${ }^{3}$ & $152.2 \square 74.1-529.6 \square$ & $150.0 \square 69.5-410.8 \square$ & 0.11 \\
Baseline platelet count, median (range), K/uL & $162 \square 77-441 \square$ & $166 \square 69-532 \square$ & 0.90 \\
\hline
\end{tabular}

Table2. The impact on splenomegaly and thrombocytopenia for Bevacizumab and nonbevacizumab cohort

\begin{tabular}{|c|c|c|c|c|c|c|}
\hline \multirow[t]{2}{*}{ outcomes } & \multicolumn{3}{|c|}{ Bevacizumab cohort $(n=73)$} & \multicolumn{3}{|c|}{ Nonbevacizumab cohort $(\mathrm{n}=80)$} \\
\hline & $\begin{array}{l}\text { Oxaliplatin- } \\
\text { based chemo } \\
(\mathrm{n}=41)\end{array}$ & $\begin{array}{l}\text { Irinotecan- } \\
\text { based chemo } \\
(n=32)\end{array}$ & $\begin{array}{l}P \text { - } \\
\text { value }\end{array}$ & $\begin{array}{l}\text { Oxaliplatin- } \\
\text { based chemo } \\
(n=57)\end{array}$ & $\begin{array}{l}\text { Irinotecan- } \\
\text { based chemo } \\
(n=23)\end{array}$ & $\begin{array}{l}P \text { - } \\
\text { value }\end{array}$ \\
\hline $\begin{array}{l}\text { six-month cumulative incidence rates of } \\
\text { splenic enlargement of } 10 \%, \% \text { (No.) }\end{array}$ & $19.5,(8)$ & $28.1,(9)$ & 0.59 & $66.7,(38)$ & $26.1,(6)$ & 0.08 \\
\hline $\begin{array}{l}\text { six-month cumulative incidence rates of } \\
\text { thrombocytopenia, \% (No.) }\end{array}$ & $31.7,(13)$ & $59.4,(19)$ & 0.20 & $77.2,(44)$ & $8.7,(2)$ & $<0.01$ \\
\hline $\begin{array}{l}\text { six-month cumulative incidence rates of } \\
\text { grade } 1 \text { thrombocytopenia, \% (No.) }\end{array}$ & 22.0, (9) & $46.9,(15)$ & 0.16 & $57.9,(33)$ & $8.7,(2)$ & 0.01 \\
\hline $\begin{array}{l}\text { six-month cumulative incidence rates of } \\
\text { grade } 2 \text { thrombocytopenia, \% (No.) }\end{array}$ & $9.8,(4)$ & $12.5,(4)$ & 1.00 & $19.3,(11)$ & 0 & 0.06 \\
\hline $\begin{array}{l}\text { six-month cumulative incidence rates of } \\
\text { grade } 3 \text { thrombocytopenia, \% (No.) }\end{array}$ & 0 & 0 & - & 0 & 0 & - \\
\hline
\end{tabular}

Table3. Characteristics of patients for Oxaliplatin-treated group and Irinotecan-treated group

\begin{tabular}{|c|c|c|c|c|c|c|}
\hline \multirow[t]{2}{*}{ characteristics } & \multicolumn{3}{|c|}{ Oxaliplatin-based chemotherapy $(n=98)$} & \multicolumn{3}{|c|}{ Irinotecan-based chemotherapy $(\mathrm{n}=55)$} \\
\hline & $\begin{array}{l}\text { BEV } \\
\text { cohort }(n=41)\end{array}$ & $\begin{array}{l}\text { Non-BEV } \\
\text { cohort }(n=57)\end{array}$ & $\begin{array}{l}P \text { - } \\
\text { value }\end{array}$ & $\begin{array}{l}\text { BEV } \\
\text { cohort }(n=32)\end{array}$ & $\begin{array}{l}\text { Non-BEV } \\
\text { cohort }(n=23)\end{array}$ & $\begin{array}{l}P \text { - } \\
\text { value }\end{array}$ \\
\hline $\begin{array}{l}\text { Age, median (range), y } \\
\text { Sex, No.(\%) }\end{array}$ & $63 \square 51-79 \square$ & $63 \square 53-80 \square$ & 0.83 & $58(53-79)$ & $62(55-89)$ & 0.18 \\
\hline Female & 13ロ31.7ロ & $19 \square 33.3 \square$ & 1.00 & $11(34.4)$ & $12(52.2)$ & 0.27 \\
\hline Male & $28 \square 68.3 \square$ & 38ロ66.7ロ & & $21(65.6)$ & $11(47.8)$ & \\
\hline BMI, median(range), kg/m² & $\begin{array}{l}20.9(15.5- \\
28.2)\end{array}$ & 21.3(15.9-26.4) & 0.62 & $21.7(16.8-29.2)$ & $22.9(18.7-33.8)$ & 0.09 \\
\hline Tumor site, No.(\%) & & & & & & \\
\hline Colon & $24 \llbracket 58.5 \square$ & 31प54.4】 & 0.84 & $21(65.6)$ & $12(52.2)$ & 0.41 \\
\hline Rectum & 17ロ41.5ロ & $26 \square 45.6 \square$ & & $11(34.4)$ & $11(47.8)$ & \\
\hline Chemotherapy cycles, median (range) & $6 \square 6-24 \square$ & $6(6-15)$ & 0.33 & $6(6-19)$ & $7(6-16)$ & 0.23 \\
\hline $\begin{array}{l}\text { Baseline spleen size, median (range), } \\
\mathrm{cm}^{3}\end{array}$ & $\begin{array}{l}174.4 \square 76.4- \\
382.8 \square\end{array}$ & $208.0(76.7-525.6)$ & 0.35 & $\begin{array}{l}160.1(83.5- \\
529.6)\end{array}$ & $\begin{array}{l}153.6(101.9- \\
263.7)\end{array}$ & 0.18 \\
\hline $\begin{array}{l}\text { Baseline platelet count, median } \\
\text { (range), K/uL }\end{array}$ & $159 \square 77-441 \square$ & $166(69-461)$ & 0.84 & $164(86-309)$ & $183(102-532)$ & 0.55 \\
\hline
\end{tabular}


Table4. The impact of bevacizumab on splenomegaly and thrombocytopenia for Oxaliplatin-treated group and Irinotecan-treated group

\begin{tabular}{|c|c|c|c|c|c|c|c|}
\hline \multirow{2}{*}{\multicolumn{2}{|c|}{ outcomes }} & \multicolumn{3}{|c|}{ Oxaliplatin-based chemotherapy $(\mathrm{n}=98)$} & \multicolumn{3}{|c|}{ Irinotecan-based chemotherapy $(\mathrm{n}=55)$} \\
\hline & & $\begin{array}{l}\text { Bevacizumab } \\
\text { cohort }(\mathrm{n}=41)\end{array}$ & $\begin{array}{l}\text { Nonbevacizumab } \\
\text { cohort }(\mathrm{n}=57)\end{array}$ & $\begin{array}{l}P \text { - } \\
\text { value }\end{array}$ & $\begin{array}{l}\text { Bevacizumab } \\
\text { cohort }(n=32)\end{array}$ & $\begin{array}{l}\text { Nonbevacizumab } \\
\text { cohort }(n=23)\end{array}$ & $\begin{array}{l}P \text { - } \\
\text { value }\end{array}$ \\
\hline \multicolumn{2}{|c|}{$\begin{array}{l}\text { six-month cumulative incidence rates of } \\
\text { splenic enlargement of } 10 \%, \% \text { (No.) }\end{array}$} & $19.5,(8)$ & $66.7,(38)$ & 0.01 & $28.1,(9)$ & $26.1,(6)$ & 1.00 \\
\hline \multicolumn{2}{|c|}{$\begin{array}{l}\text { six-month cumulative incidence rates of } \\
\text { splenic enlargement of } 20 \%, \% \text { (No.) }\end{array}$} & 0 & $50.1,(29)$ & 0.00 & $18.8,(6)$ & $17.4,(4)$ & 1.00 \\
\hline \multicolumn{2}{|c|}{$\begin{array}{l}\text { six-month cumulative incidence rates of } \\
\text { splenic enlargement of } 30 \%, \% \text { (No.) }\end{array}$} & 0 & $27.9,(12)$ & $<0.01$ & $6.3,(2)$ & 8.7, (2) & 1.00 \\
\hline \multicolumn{2}{|c|}{$\begin{array}{l}\text { median time to splenic enlargement of } \\
10 \% \text { or greater, } \mathrm{d}(\mathrm{m})\end{array}$} & $120,(4.0)$ & $103(3.4)$ & 0.85 & $130(4.3)$ & $140(4.7)$ & 0.80 \\
\hline \multicolumn{2}{|c|}{$\begin{array}{l}\text { six-month cumulative incidence rates of } \\
\text { thrombocytopenia, \% (No.) }\end{array}$} & $31.7,(13)$ & $77.2,(44)$ & 0.02 & $59.4,(19)$ & $8.7,(2)$ & 0.01 \\
\hline \multirow{2}{*}{\multicolumn{2}{|c|}{$\begin{array}{l}\text { six-month cumulative incidence rates of } \\
\text { grade } 1 \text { thrombocytopenia, \% (No.) } \\
\text { six-month cumulative incidence rates of } \\
\text { grade } 2 \text { thrombocytopenia, \% (No.) }\end{array}$}} & $22.0,(9)$ & $57.9,(33)$ & 0.02 & $46.9,(15)$ & 8.7, (2) & 0.04 \\
\hline & & $9.8,(4)$ & $19.3,(11)$ & 0.40 & $12.5,(4)$ & 0 & 0.15 \\
\hline \multirow{2}{*}{\multicolumn{2}{|c|}{$\begin{array}{l}\text { six-month cumulative incidence rates of } \\
\text { grade } 3 \text { thrombocytopenia, \% (No.) } \\
\text { median time to thrombocytopenia, } d(m)\end{array}$}} & 0 & 0 & - & 0 & 0 & - \\
\hline & & $23 d(0.8 m)$ & $33 \mathrm{~d}(1.1 \mathrm{~m})$ & 0.02 & $10 \mathrm{~d},(0.3 \mathrm{~m})$ & $64 \mathrm{~d}(2.1 \mathrm{~m})$ & 0.01 \\
\hline \multirow{2}{*}{$\begin{array}{l}\text { six-month cumulative } \\
\text { incidence rates of } \\
\text { splenic enlargement of } \\
10 \%, \% \text { (No.) }\end{array}$} & $\begin{array}{l}\text { Patients with } \\
\text { liver metastasis }\end{array}$ & $26.106 \square$ & $60.6 \square 20 \square$ & 0.14 & $36.4 \square 4 \square$ & $20.0 \square 2 \square$ & 0.66 \\
\hline & $\begin{array}{l}\text { Patients } \\
\text { withouit liver } \\
\text { metastasis }\end{array}$ & $11.1 \square 2 \square$ & $75.0018 \square$ & 0.01 & $23.8 \square 5 \square$ & $30.8 \square 4 \square$ & 1.00 \\
\hline \multirow{2}{*}{$\begin{array}{l}\text { six-month cumulative } \\
\text { incidence rates of } \\
\text { thrombocytopenia, \% } \\
\text { (No.) }\end{array}$} & $\begin{array}{l}\text { Patients with } \\
\text { liver metastasis }\end{array}$ & $43.5 \square 10 \square$ & $75.8 \square 25 \square$ & 0.27 & 63.6ロ7ロ & $10.001 \square$ & 0.11 \\
\hline & $\begin{array}{l}\text { Patients without } \\
\text { liver metastasis }\end{array}$ & 16.7ロ3ロ & $79.2 \square 19 \square$ & 0.03 & $57.1012 \square$ & 7.7०10 & 0.07 \\
\hline \multirow[t]{2}{*}{$\begin{array}{l}\text { six-month cumulative } \\
\text { incidence rates of } \\
\text { thrombocytopenia, \% } \\
\text { (No.) }\end{array}$} & $\begin{array}{l}\text { patients with } \\
\text { splenic } \\
\text { enlargement of } \\
\text { more than } 10 \%\end{array}$ & $50.0 \square 4 \square$ & $78.9 \llbracket 30 \square$ & 0.54 & $66.7(6)$ & $9.1(1)$ & 0.09 \\
\hline & $\begin{array}{l}\text { patients with } \\
\text { reduced splenic } \\
\text { volume }\end{array}$ & $35.0(7)$ & $67.7(10)$ & 0.37 & $50.0(7)$ & $8.3(1)$ & 0.12 \\
\hline
\end{tabular}

\section{Figures}


Fig 1A

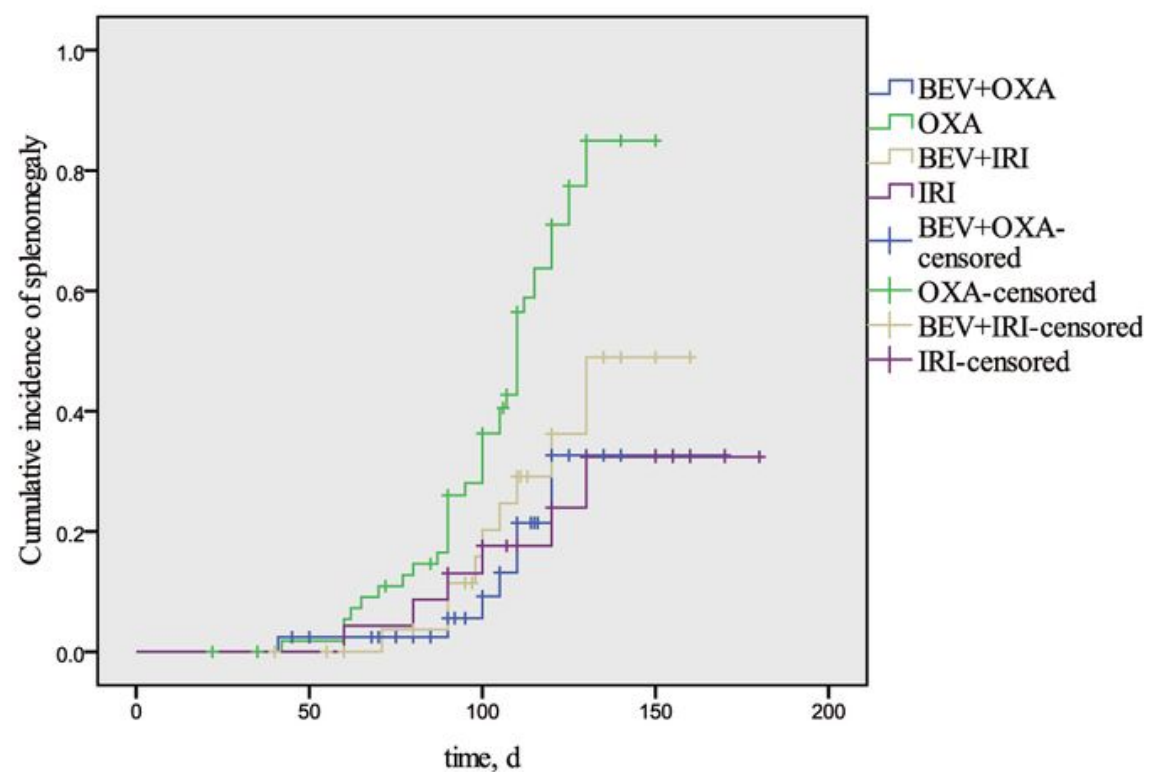

Fig 1B

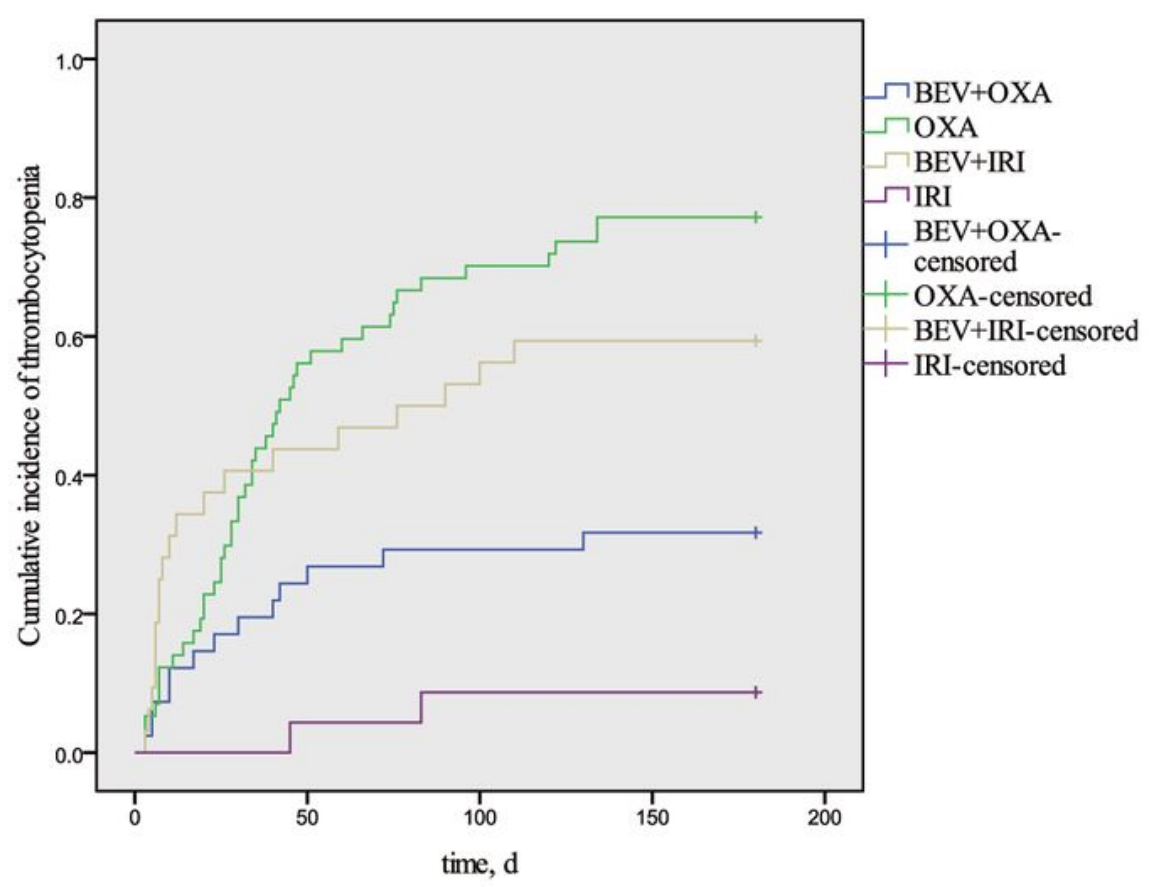

Fig 1. A. Cumulative incidences of splenomegaly defined as $10 \%$ or greater increase in spleen volume in $\mathrm{BEV}+\mathrm{OXA}, \mathrm{OXA}, \mathrm{BEV}+\mathrm{IRI}$ and IRI subgroups; $\mathrm{B}$. Cumulative incidences of thrombocytopenia in BEV+OXA, OXA, BEV+IRI and IRI subgroups

\section{Figure 1}

A. Cumulative incidences of splenomegaly defined as $10 \%$ or greater increase in spleen volume in $B E V+O X A, O X A, B E V+I R I$ and IRI subgroups; $B$. Cumulative incidences of thrombocytopenia in $B E V+O X A$, $O X A, B E V+I R I$ and IRI subgroups. 


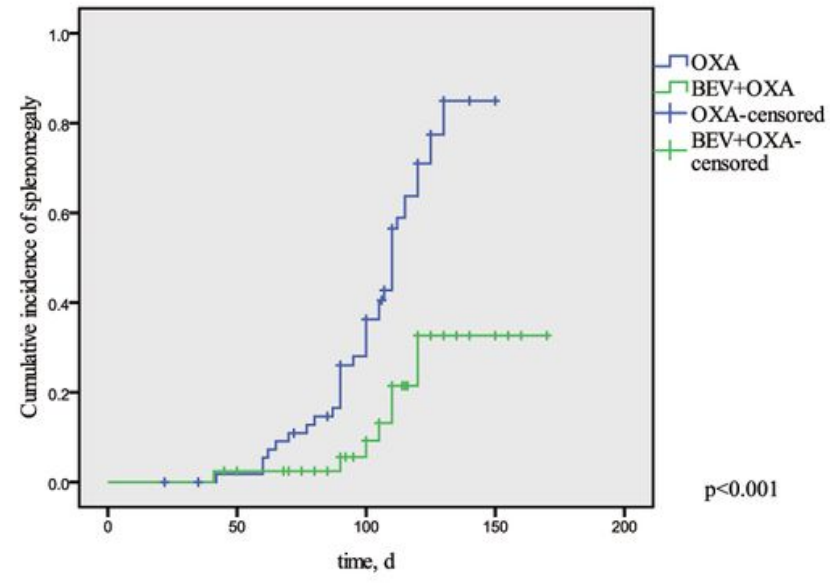

Fig 2C

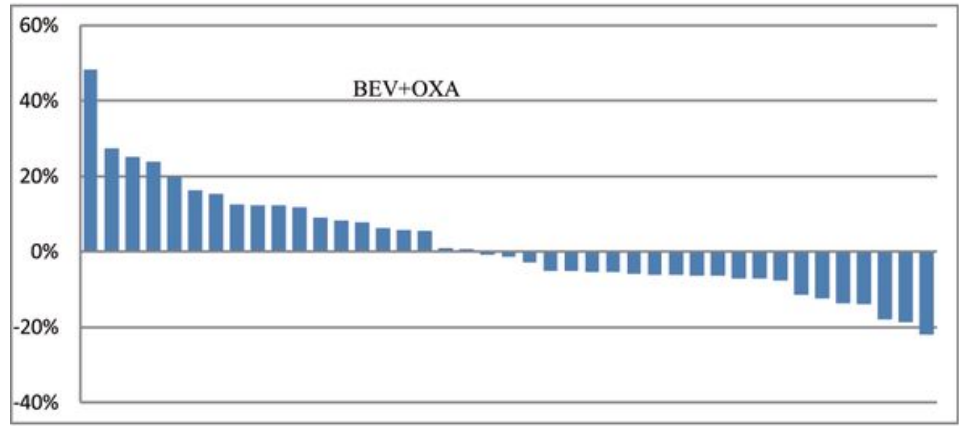

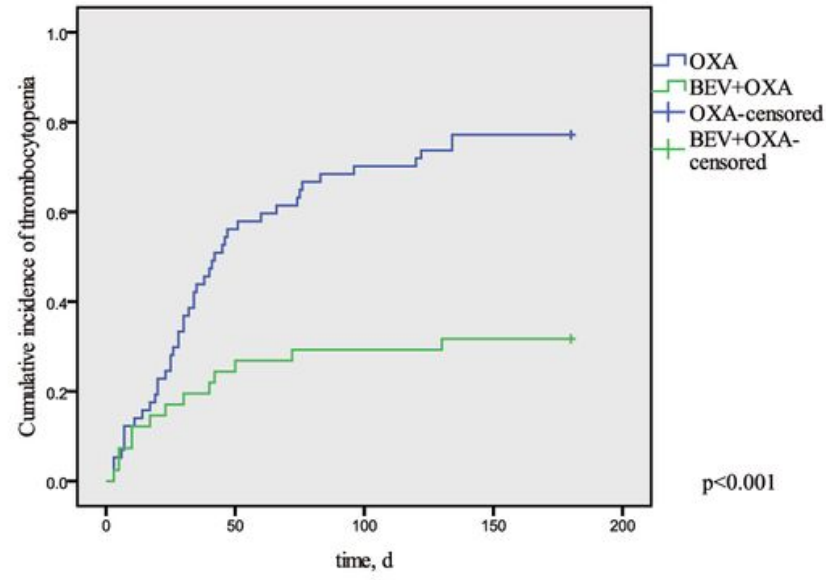

Fig 2D

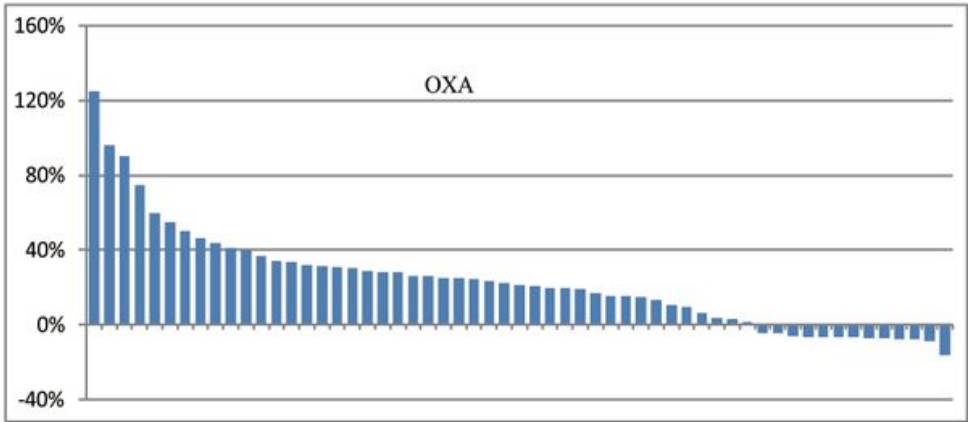

Fig 2. A. Cumulative incidences of splenomegaly defined as $10 \%$ or greater increase in spleen volume in BEV+OXA and OXA subgroups; B. Cumulative incidences of thrombocytopenia in BEV+OXA and OXA subgroups. C. Maximal percentage change in spleen size in BEV+OXA subgroup, D. Maximal percentage change in spleen size in OXA subgroup.

\section{Figure 2}

A. Cumulative incidences of splenomegaly defined as $10 \%$ or greater increase in spleen volume in $B E V+O X A$ and OXA subgroups; $B$. Cumulative incidences of thrombocytopenia in BEV+OXA and OXA subgroups. C. Maximal percentage change in spleen size in BEV+OXA subgroup, D. Maximal percentage change in spleen size in OXA subgroup. 
Fig $3 \mathrm{~A}$

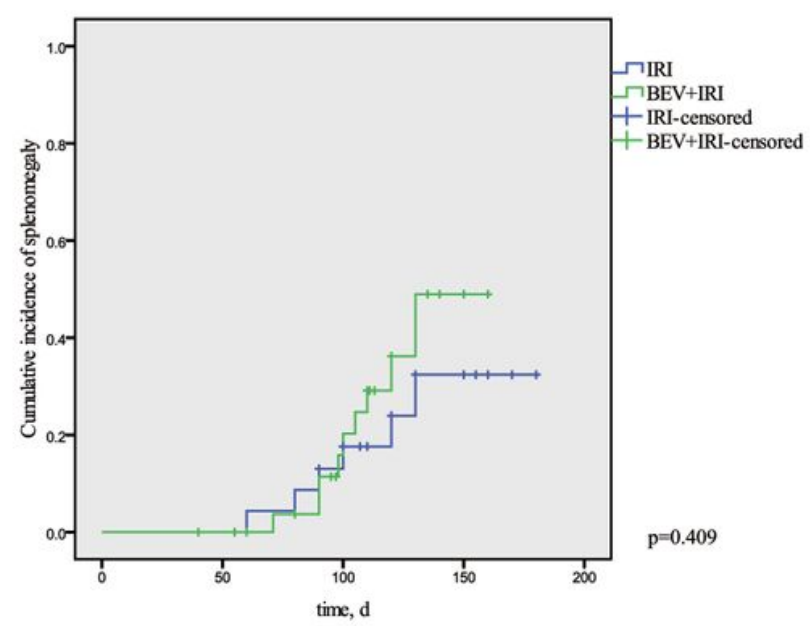

Fig $3 \mathrm{C}$

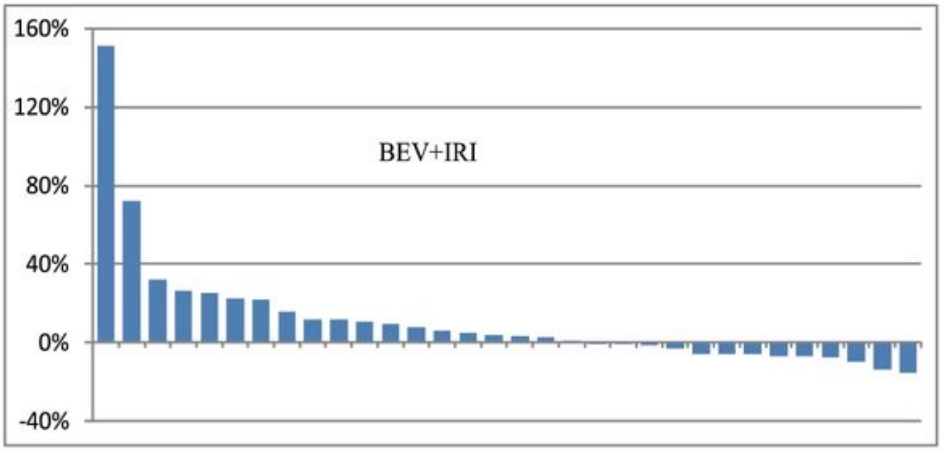

Fig 3B

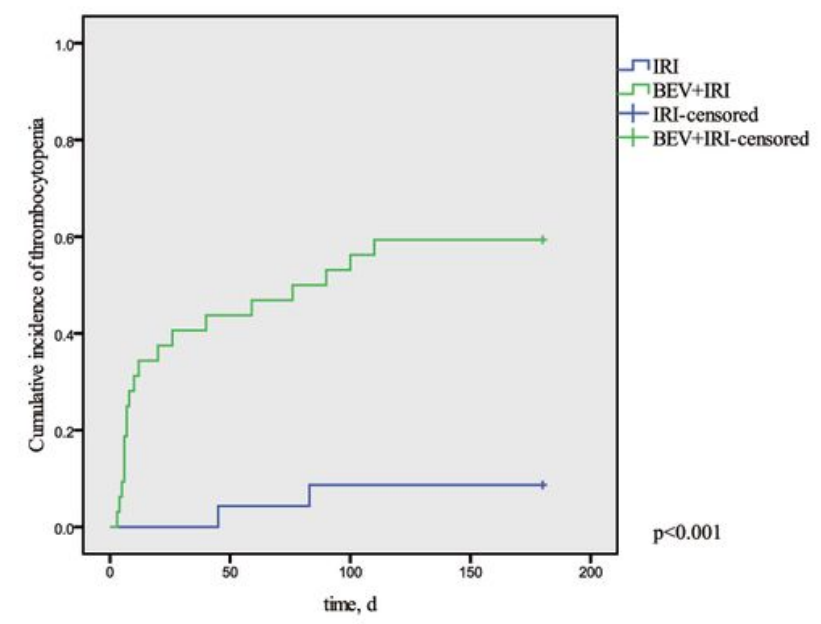

Fig 3D

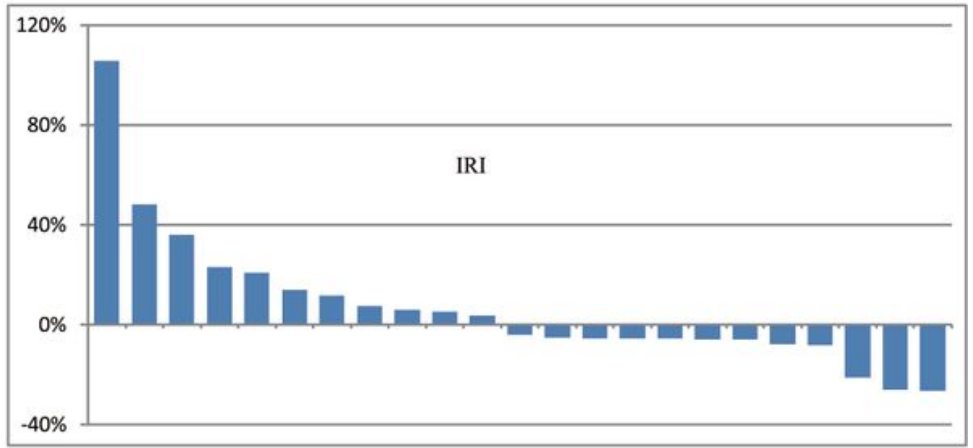

Fig 3. A. Cumulative incidences of splenomegaly defined as $10 \%$ or greater increase in spleen volume in BEV+IRI and IRI subgroups; B. Cumulative incidences of thrombocytopenia in BEV+ IRI and IRI subgroups; C. Maximal percentage change in spleen size in BEV+IRI subgroup; D. Maximal percentage change in spleen size in IRI subgroup.

\section{Figure 3}

A. Cumulative incidences of splenomegaly defined as $10 \%$ or greater increase in spleen volume in $B E V+I R I$ and IRI subgroups; $B$. Cumulative incidences of thrombocytopenia in BEV+ IRI and IRI subgroups; C. Maximal percentage change in spleen size in BEV+IRI subgroup; D. Maximal percentage change in spleen size in IRI subgroup. 